\title{
Investment Strategies, Fund Performance and Portfolio Characteristics
}

\author{
Stefan Engström* \\ January 29, 2004 \\ SSE/EFI Working Paper Series in Economics and Finance No 554
}

\begin{abstract}
This paper provides extensive evidence on portfolio characteristics of mutual funds and studies the relation between fund performance and the fund manager's investment strategy. The results show that neither momentum characteristics nor the valuation of stocks can explain differences in fund performance. However, the paper finds a negative firm-size effect that partly explains previous findings of a negative fund-size effect. Moreover, the results show a positive relation between performance and the degree of diversification within the fund portfolio. However, diversification by including non-listed stocks does not enhance performance.
\end{abstract}

Keywords: Diversification, Portfolio Evaluation, Investment Strategies, Momentum.

JEL Classifications: G11, G12, G23.

\footnotetext{
* I would like to thank Magnus Dahlquist, Peter Englund, Frans de Roon, and Paul Söderlind for their helpful comments and suggestions. I gratefully acknowledge financial support from Bankforskningsinstitutet. Address: Stockholm School of Economics, Department of Finance, P.O. Box 6501, S-113 83 Stockholm, Sweden, Phone: +46 7065694 74, Fax: +46 831 23 27, E-mail: stefan.engstrom@hhs.se
} 


\section{Introduction}

Many recent studies have increased our understanding of mutual fund performance by trying to find some of its determinants. These studies mainly analyze the relation between fund performance and fund properties, such as fund size, fees, trading activity, flows, and past returns. However, one obviously important yet unexplored fund property is the fund's investment strategy, which we characterize based on portfolio holdings. In this study, I extend the current evidence on mutual fund performance by investigating the relation between fund managers' investment strategies and performance. This relation is examined for overall performance, based on traditional evaluation techniques, and for strategic as well as tactical performance, based on Engström (2004).

This study provides new evidence on how asset pricing anomalies might affect the performance of mutual funds, since some of the explored portfolio characteristics are related to these anomalies. Specifically, it examines the performance of buy-and-hold portfolios considering the effect of past asset returns, firm size, and the valuation of stocks.

The empirical literature has previously found evidence of different asset pricing anomalies. For instance, Grinblatt, Titman and Wermers (1995), and Jegadeesh and Titman (1993) show that momentum is profitable, that is, buying past winners creates abnormal returns. The results in Falkenstein (1996) show that U.S. mutual fund managers try to create abnormal performance by pursuing momentum strategies. However, Conrad and Kaul (1998), and DeBondt and Thaler (1985) show that contrarian strategies are usually profitable at long horizons. Moreover, investing in small companies seems to create abnormal returns. This 'small-firm effect' was first documented by Banz (1981), who studied small firms in the U.S Heston, Rouwenhorst and Wessels (1995) found that this effect also holds for international returns. Other studies have found pricing anomalies related to accounting information. Fama and French (1992) show that firms with high book-to-market values produce high risk- 
adjusted returns for U.S. stocks; Fama and French (1998) show that this 'value-premium' holds internationally.

This study also offers new evidence on the relation between other characteristics of the fund portfolio and performance. For instance, can a diversified portfolio aid performance? Do investments outside the fund's primary investment universe enhance performance? How do cash holdings affect performance? These issues have not been extensively examined in the literature. However, Elton, Gruber, Das and Hlavka (1993) show that the high performance in Ippolito (1989) is due to investments outside the funds' primary investment universe.

In order to explore how the fund manager's investment strategy affects performance, this study employs a sample of 112 equity funds that invested in Sweden sometime between 1996 and 2000. The sample is free from survivorship bias. The results show that, contrary to U.S. evidence, investment strategies based on momentum and the valuation of stocks cannot explain observed differences in performance. However, the study finds a negative firm-size effect that partly explains previous findings of a negative fund-size effect. Further, no significant relation between performance and momentum characteristics or valuation of stocks or firm size is found for the buy-and-hold portfolio. The results also show that funds consisting of more diversified portfolios perform better than funds with concentrated portfolios. However, this study does not find any significant relation between the fund's performance and the extent to which it invests outside its primary investment universe. Hence, diversification by including non-listed stocks does not enhance performance. This paper also shows that large cash holdings are positively related to the tactical performance of funds.

The rest of the paper is organized as follows. Section 2 presents overall characteristics of Swedish mutual funds and fund-specific data that are used in the paper. In Section 3, we evaluate the performance of the sample of funds. Section 4 explores the relation between performance and the funds' investment strategies. Finally, Section 5 presents the conclusions. 


\section{Data}

\subsection{The Swedish Industry and the Sample of Funds}

Evaluations of the Swedish mutual fund industry are important for many reasons. It is a relatively young industry and consists of less sophisticated funds than the U.S. mutual fund industry. The development of the Swedish mutual fund industry mainly occurred in the 1990s, and especially during the second half. At the beginning of 1995, total assets managed within this industry amounted to SEK 207 billion; at the end of 2000 this had increased to SEK 898 billion (the price of a U.S. dollar was about SEK 10 in the year 2000). Compared with many other nationalities, Swedes prefer equity funds, which amount to $70 \%$ of the total industry. The equity fund industry has traditionally consisted of country, regional, or global funds, but funds focusing on a specific industry gained increased attention during the late 1990s.

During the fall of 2000, Sweden launched a new pension system that obliged 4.4 million Swedes to invest in mutual funds, effectively making most Swedes holders of mutual fund shares. This pension system will ensure net inflows of more than SEK 13 billion per year to the industry, and these inflows have naturally attracted many new mutual fund companies to the Swedish market.

The sample of funds consists of all mutual funds that have focused their investments on the Swedish market sometime during the five-year period from 1996 to 2000 . The total number of funds is 112; of these, 97 invest in the broad Swedish equity market (Sweden funds) and 15 focus their investments on small Swedish firms (Small Cap funds). All the funds meet the same investment policy, i.e., the UCITS terms (Undertakings for Collective Investments in Transferable Securities), and are therefore comparable to U.S. funds, which meet similar terms. The UCITS terms were introduced in 1985 (Undertakings for Collective Investments in Transferable Securities). These terms state that the funds are not allowed to 
hold a single stock worth more than $10 \%$ of their total assets. Moreover, they are only allowed to hold stocks worth more than $5 \%$ of their total assets to a maximum of $40 \%$ of total assets. The terms also state that as to $75 \%$ of the assets of the fund, the fund cannot acquire more than $10 \%$ of the voting securities of any issuer and cannot invest more than $5 \%$ of total fund assets in any one issuer. Hence, the minimum number of stocks a diversified U.S. mutual fund and a European (UCITS) mutual fund must own is 16 . Morever, the average fee of about $1.5 \%$ per year is also similar to the fees of U.S. equity funds. Some funds also charge exit and loading fees, but this is not very common. All funds are open-end funds and most funds have low requirements on the initial investment.

The performance evaluation is based on weekly data of the funds' net asset values (NAV) obtained from the Trust database of Findata. The NAV includes reinvested dividends and there is no tax dilution. I use two benchmarks in the evaluation: the 'General Market' and 'Small Firms'. The General Market is a value-weighted index that covers all stocks listed on the Stockholm Stock Exchange (SSE). This index does not allow weights of above 10\% for a single firm, which is the same as the regulations that apply to mutual funds. During the fiveyear sample period, the total return on the General Market was $170 \%$ or $19 \%$ per year in excess of the risk-free interest rate that is approximated by the 7-day STIBOR. This can be compared with the return on the Small Firms index that was $130 \%$ during the sample period or $16 \%$ per year in excess of the risk-free interest rate. The value-weighted Small Firms index consists of all firms traded on the SSE with a market value of less than SEK 10 billion. ${ }^{1,2}$ Weekly return data including dividends of the benchmarks and stocks are obtained from the Trust database of Findata.

\footnotetext{
${ }^{1}$ I thank Anders Andersson and Paul Söderlind for their help in putting together the index

${ }^{2}$ The maximal market capitalization varies over time, SEK 10 billion is a global maximum and was observed at the beginning of 2000 .
} 


\subsection{Investment Strategies}

In this study I examine the relation between performance and investment strategies, defined by characteristics of fund portfolios. The analysis is conducted by first calculating value-weighted averages of stock/company characteristics for the funds' portfolio holdings. The funds' portfolio holdings are obtained from annual reports ${ }^{3}$ and data on stock characteristics taken from Datastream. I use characteristics that are related to the stocks, accounting information of the companies, and structure of the fund portfolio. The investment strategies that are evaluated are based on the following portfolio characteristics:

(i) Past return. I use two different horizons of past return, namely three months and one year. No return is calculated if the stock has a shorter listing history than the relevant period (three month and one year).

(ii) Firm size. Two measures are used:

(a) Market value. This is total value of the stocks, in SEK billion.

(b) Liquidity risk. Average traded volume in the stock market during the past year, on a daily basis, measured in SEK billion, is used as proxy for liquidity risk.

(iii) Valuation of firms. Two measures are used:

(a) Book-to-market. This is a valuation measure of the firm. Growth stocks typically have ow measures, while value stocks have high measures. The measure is defined as book value divided by market value of equity at year-end.

(b) Dividend yield. The dividend yield is typically higher for value stocks than for growth stocks.

(iv) Diversification ratio. The minimum number of stocks a mutual fund is allowed to have is 16 . The diversification ratio is calculated as one minus the weight of the 16 largest stock holdings over total assets. This implies that the

\footnotetext{
${ }^{3}$ I thank Morningstar for their help in putting together part of the data.
} 
diversification ratio can vary between 0 and 1 , where a high measure indicates a well diversified portfolio.

(v) Other investments. This measure captures to the extent to which the fund invests in assets outside its primary investment universe. These assets are mainly nonlisted Swedish companies, but foreign stocks also appear in this measure. The measure is calculated as the weight of the fund's assets outside its primary investment universe.

(vi) Cash holdings. This measure is defined as non-stock holdings over total assets.

Table 1 shows the correlations of the characteristics of the portfolios across funds. We can see that the correlations of diversification ratio, other investments, and cash holdings are low. In contrast, there is a higher correlation of the investment strategies that are related to asset pricing anomalies. The correlations of past one year return and the other variables are similar to the correlations of past three months return, the correlations of average traded volume and the other variables are similar to the correlations of market capitalization, and the correlations dividend yield and other variables are similar to the correlations of and book-to-market ratio.

Table 2 gives the annual averages of the different characteristics of the fund portfolios. The Small Cap and Sweden funds have, on average, similar momentum, book-to-market, and dividend yield characteristics. However, firm size naturally differs between the two types of funds. The average traded volume per day of stocks in Small Cap funds is only SEK 18 million, whereas the corresponding figure for Sweden funds is SEK 251 million. A similar difference between Small Cap and Sweden funds is observed for the average market capitalization of the stocks: SEK 6 billion and SEK 87 billion, respectively. Both average traded volume and average size have increased significantly during the sample period.

Figure 1 shows that Small Cap funds have, on average, a larger share of their assets in cash: on average, 5.5\% compared with $3.6 \%$ for Sweden funds. This difference might be due to the fact that Small Cap funds have less total assets, and that the funds need to keep a certain amount of cash to handle the flows. 
The fund managers of Small Cap funds and Sweden funds make similar diversification decisions. Figure 2 shows that the diversification ratio varies mainly between $20 \%$ and $50 \%$ for both categories of funds, though the mean and median is slightly lower for Sweden funds. Interestingly, Table 2 shows that the diversification ratio has increased during the sample period. The results are similar when diversification is measured as the number of stocks. On average, both Small Cap and Sweden funds hold about 40 stocks, but the dispersion is wide. The number of stocks in the funds' portfolio is generally between 20 and 70 at the end of each year during the sample period.

In Figure 3, we notice that both Small Cap funds and Sweden funds invest to a similar extent in assets that are not traded on the Stockholm Stock Exchange (SSE). Typically, these are firms that will be traded on the SSE in the near future. The median Small Cap and median Sweden fund invest $4 \%$ of their assets in this type of firm.

\section{Performance Evaluation}

In this evalution, fund performance is measured using both the traditional unconditional alpha model, as in Jensen (1968), and the conditional alpha, following Ferson and Schadt (1996). The Ferson and Schadt (1996) measure is obtained by the following time-series regression

$$
R_{i t}-R_{f t}=\alpha_{i}+\beta_{i 0}\left(R_{b t}-R_{f t}\right)+\beta_{i 1}^{\prime} q_{t-1}\left(R_{b t}-R_{f t}\right)+\varepsilon_{i t}
$$

where $R_{i t}, R_{b t}$ and $R_{f t}$ are the return on fund $i$, the benchmark, and the risk-free asset, respectively. The predetermined information variables are denoted $q_{t-1}$. Each information variable has zero mean. The $\varepsilon_{i t}$ is a fund-specific error term. The intercept, $\alpha_{i}$, is Jensen's alpha measure or the systematic pricing error. This deviation from the benchmark model, if it is positive (negative), can be interpreted as superior (inferior) performance. The time-varying beta coefficient $\beta_{i 0}+\beta_{i 1}^{\prime} q_{t-1}$ measures the exposure to the benchmark and is a measure of the fund's systematic risk. Moreover, I employ the methods developed in Treynor and Mazuy 
(1966) and Henriksson and Merton (1981) to check whether the results are biased due to market timing.

The alpha is estimated on weekly fund returns and two benchmark portfolios are used: the General Market index and Small Firms index. The return on risk-free asset is approximated by the 7-day STIBOR. I use the de-meaned lagged market return and the level of the yield curve as information variables.

Engström (2004) decomposes overall alpha into components attributable to strategic and tactical decisions; the same method is applied here. The performance of the fund managers' strategic decisions is the risk-adjusted return of a buy-and-hold or replicating portfolio of each fund. This replicating portfolio is constructed based on observed portfolio holdings and is rebalanced annually. Further, it meets the same regulations as the true fund. Tactical performance is the risk-adjusted return on the fund in excess of its replicating portfolio.

\subsection{Empirical Results}

Figure 4 shows the distribution of the funds' overall performance. The average performance $(\alpha)$ of Small Cap funds is 3.2\%, and the corresponding average performance for Sweden funds is $1.7 \%$, when the conditional model is employed. Similar results are obtained when the unconditional model is used. However, statistically only a few funds' performance is significantly higher than zero. Interestingly, Figure 4 shows that the performance of most funds is very similar since $77 \%$ of them deliver a performance of between $-2 \%$ and $4 \%$ on an annual basis. Moreover, the performance measures are robust since the evaluation suggests that the fund managers possess neither a positive nor a negative timing ability.

The performance evaluation also shows that the average beta for Small Cap funds is close to one (towards the Small Firms index) and the average beta for Sweden funds is close to one (towards the General Market). Moreover, there is little variation in beta and, hence, 
beta is close to one for most funds. Finally, the regression results show that $90 \%$ of the funds' returns are explained by the benchmarks.

The average performance of the funds is high compared with funds in the U.S. and other European countries. The evidence in international studies suggests that once fees are deducted, the average mutual fund does not outperform a relevant index. Similar evidence is found in Engström (2003) who examines the part of the Swedish mutual fund industry that invest in Asian and European equity. However, in a previous study by Dahlquist, Engström and Söderlind (2000), evidence are found to suggest that mutual funds investing in Swedish equity perform well compared with international evidence. They show that the average performance between 1993 and 1997 was close to zero, once fees were deducted.

Moreover, the high overall performance observed is as Engström (2004) shows, due to successful tactical decisions for Small Cap funds and successful strategic decisions for Sweden funds. The average performance of tactical decisions is $3.2 \%$ and $-1.4 \%$ per year for Small Cap and Sweden funds, respectively. In contrast, the average performance of strategic decisions is $0.1 \%$ per year for Small Cap and 3.2\% for Sweden funds.

\section{Performance and Investment Strategies}

In order to analyze how the funds create performance, we study fund performance along with several different investment strategies. This is done by measuring fund performance on a year-by-year basis, using the method described in Section 3, and then relating this to annual data of portfolio characteristics. Annual portfolio holdings are observed at the end of each year from 1995 to 1999 . I let these observed portfolio holdings serve as proxy for the fund managers' investment strategy the coming year. That is, the end of year portfolio holdings in 1995 serves as proxy for the investment strategy during 1996, and so on.

We can express the panel data regression model as

$$
\hat{\alpha}_{i T}-\overline{\hat{\alpha}}_{T}=\gamma_{0}+\gamma_{1}\left(z_{i T}-\bar{z}_{T}\right)+\xi_{i T},
$$


where $\hat{\alpha}_{i T}$ is the estimated alpha for fund $i$ in year $T$, and $z_{i T}$ is the characteristic of the portfolio at the beginning of year $T$, which is a proxy for the investment strategy. I allow for fixed (year) effects by subtracting the mean of the alpha and the attribute during a year, denoted by $\overline{\hat{\alpha}}_{T}$ and $\bar{z}_{T}$, respectively. The relation between alpha and the investment strategy is evaluated by a weighted least squares (WLS) approach where each observation is weighted by the reciprocal of its residual standard deviation from the performance regression (equation 1). I use the WLS approach because the alphas are generated variables that contain measurement errors. This will introduce heteroskedasticity since the different alphas are measured with varying degrees of precision. The implication of this is that ordinary least squares (OLS) are inefficient and that the traditional estimates of the standard errors are misleading.

I also measure the performance of trading strategies based on fund characteristics. This offers further evidence on the cross-sectional differences and helps to quantify them economically. The funds are first ranked according to the attribute and then divided into two equally-weighted portfolios; low attribute funds make up one, and higher attribute funds the other. The cut-off points for Small Cap funds are below the 33rd percentile and above the 67th percentile; for Sweden funds the cut-off points are below the 25 th percentile and above the 75th percentile. Moreover, I also use the latter as cut-off points when evaluating all the funds. This choice of cut-off points strikes a good balance between getting a large number of funds in each of the two portfolios and making the two portfolios distinctly different. ${ }^{4}$ Based on the cut-off points, I construct a fictitious zero-cost portfolio by buying the "high" portfolio and short-selling of the "low" portfolio. This zero-cost portfolio is held for one year, after which, the sorting procedure is repeated, new portfolios are created and held for the subsequent year, and so on. Note that all the funds (even those that exit the sample during the period) are used in these strategies.

\footnotetext{
${ }^{4}$ I use different cut-off points for Small Cap funds and Sweden funds since the number of funds within each investment objective differs significantly.
} 


\subsection{Asset Pricing Anomalies}

In this section, I discuss the results in Tables $3-5$ and examine how fund performance is affected by investment strategies that are related to the well-known momentum effect in equity prices, the firm size effect, and the value premium. The tables show the results for joint evaluation of all the funds. However, I comment on the corresponding results for Small Cap and Sweden funds separately.

\subsubsection{Momentum in Equity Prices}

In this section, we explore how the momentum effect might affect the performance of mutual funds in the Swedish market. Table 3 on the next page presents results on the relation between past return characteristics and fund performance. Two different horizons of past return are examined: one three-month and one twelve-month (based on the portfolio holdings at the beginning of each year). Further, the table divides the results into overall, strategic, and tactical performance.

The momentum effect is one of the most explored asset pricing anomalies. Jegadeesh and Titman (1993) show that momentum is profitable, that is buying past winners creates abnormal returns. However, the momentum effect is short-lived and abnormal returns can be created at the three- to twelve-month horizon. In contrast, Conrad and Kaul (1998) and DeBondt and Thaler (1985) show that contrarian strategies are usually profitable at longer horizons. Based on this evidence, we could expect that professional portfolio managers use this information and choose a portfolio that is biased towards momentum stocks. The empirical evidence supports this hypothesis; Grinblatt, Titman and Wermers (1995), and Falkenstein (1996) show that U.S. mutual funds actually have portfolios that are biased 
towards momentum stocks. Interestingly, Grinblatt, Titman and Wermers (1995) show that funds investing in momentum stocks realized better returns.

I obtain statistically significant results in the cross-sectional regression of overall performance and past stock returns, but this result cannot be established when the trading strategy is employed. This difference between the cross-sectional regression and the trading strategy is due to outliers. The average performance of funds with low past stock returns is similar to the average performance of funds with high past stock returns. In contrast, the median performance of funds with low past stock returns is higher than the median performance of funds with high past stock returns. Hence, this result suggests a weak negative relation between past one year returns and overall performance. Similar results are obtained when only Sweden funds are evaluated, whereas no relation between past returns and overall performance is found for Small Cap funds.

Table 3 shows that the results for tactical performance are similar to the overall performance measure. However, a weak positive relation is found between tactical performance and past one year return when Small Cap funds are examined.

The results are somewhat different when strategic performance is examined. Table 3 shows no statistically significant relation between past returns and strategic performance. This evidence is similar to Rouwenhorst (1998), who explores momentum in an international setting and concludes that momentum is not present in Sweden. However, I find a negative relation between past returns and strategic performance when I examine Small Cap funds separately. This result is statistically significant both in the cross-sectional regressions and when the trading strategies are employed. In contrast, there is no significant relation between past returns and strategic performance for Sweden funds. 


\subsubsection{Firm Size}

In this section, we study how performance might be affected by investment strategies that are based on firm size (market capitalization) or liquidity risk (average traded volume). Table 4 presents results on how these investment strategies explain differences in fund performance in Sweden. Two different measures are used: value-weighted market capitalization and value-weighted average traded volume. Further, the table presents the results for overall, strategic, and tactical performance.

Another often cited asset pricing anomaly is the size or small-firm effect. The pioneer work was done by Banz (1981), who studied small firms in the U.S. Banz finds that investing in small firms creates abnormal returns. Interestingly, Heston, Rouwenhorst and Wessels (1995) show that the small-firm effect holds in an international setting. Moreover, Brennan, Chordia and Subrahmanyam (1997) support these results by discovering a negative relation between firm size and risk-adjusted returns on individual securities. However, they show that the negative size effect disappears when the dollar volume of trading is included in the regression. This suggests that the size effect is actually a trading volume effect that could be interpreted as a proxy for liquidity risk. In contrast to the momentum effect, this anomaly does not appear to be taken advantage of by professional investors. Falkenstein (1996) finds that U.S. fund managers have a significant preference for stocks with high visibility, as measured by the amount of coverage in newspaper articles. These firms normally have a large market capitalization and low liquidity risk.

The results suggest that there is a weak negative relation between firm size or traded volume and overall performance for funds in Sweden. However, I find no relation between firm size and performance when I examine Small Cap and Sweden funds separately.

Moreover, firm size cannot explain differences in strategic performance. Almost all the measures were found to be insignificant. The only measure that is statistically significant is when the strategic performance of Sweden funds is examined in a cross-sectional setting versus firm size. 
In contrast, I find a very strong negative relation between firm size and tactical performance. Table 4 shows that all measures, both strategies based on market capitalization and average traded volume, are statistically significant in the cross-sectional setting and when the trading strategies are employed. However, I do not find a statistically significant relation between tactical performance and firm size when I examine Small Cap funds and Sweden funds separately. This suggests that the negative relation between firm size and tactical performance is mainly caused by the fact that Small Cap funds' tactical performance is much higher than that of Sweden funds. Interestingly, this negative effect can explain part of the negative size-of-fund effect that was found by Dahlquist, Engström and Söderlind (2000), since smaller funds invest in smaller stocks.

\subsubsection{Valuation of Firms}

In this section, I explore how the performance is affected by investment strategies that are based on the valuation of the firms. I use book-to-market values and dividend yields as proxies for the valuation of the firms.

The existing literature has identified an asset pricing anomaly which is related to the valuation of the firm. Based on the valuation, firms can be classified as value or growth firms. Value firms have high ratios of book-to-market equity and high dividend yield. Many studies of the U.S. stock market have found that value stocks outperform growth stocks (see e.g., Fama and French (1992), Fama and French (1996), and Lakonishok, Shleifer and Vishny (1994)). This anomaly is often referred to as the book-to-market effect or the value premium. Interestingly, Fama and French (1998) conclude that this asset pricing anomaly holds in an international setting.

Table 5 presents results on the relation between the valuation of the stocks in the managed portfolio and the performance of funds in Sweden. The value-weighted book-tomarket ratio and the value-weighted dividend yield of the stocks in the portfolio at the 
beginning of the year are used as proxies for the fund's investment strategy. As before, the table presents the results for overall, strategic, and tactical performance.

The cross-sectional examination of book-to-market ratios and dividend yield versus overall performance suggests that there is a value premium in Sweden (see Table 5). However, the relation is weak, since we do not obtain significant results when the trading strategies are employed. Similar results are obtained when only Sweden funds are examined. In contrast, no relation between the valuation of firms and overall fund performance is found when only Small Cap funds are examined.

Table 5 shows a weak positive relation between strategic performance and the valuation of firms when all the funds are jointly examined. A similar result is obtained for Sweden funds. In contrast, I find no significant results for Small Cap funds that would prove the existence of a value premium.

The results suggest that funds with more value stocks in their portfolios have higher tactical performance. However, the only statistically significant findings that support this are obtained when all the funds are jointly examined. This suggests that the result is due to the higher book-to-market ratios and higher tactical performance of Small Cap funds.

\subsection{Other Investment Strategies}

This section explores the relation between the performance of the funds and other characteristics of the managed portfolio. Three characteristics are examined: the degree of diversification, investments outside the funds' primary investment universe, and the funds' cash holdings. The results are mainly related to overall and tactical performance, since there are no significant results for strategic performance. Table 6 shows the results for joint evaluation of all the funds. However, I comment on the corresponding results for Small Cap and Sweden funds separately. 


\subsubsection{Diversification Ratio}

In this section, I want to study how fund managers' diversification strategy affects performance in the performance evaluation. Holding a less diversified portfolio implies a higher probability/risk of experiencing both a higher and lower return. In Sweden, some recently launched funds have an investment objective restricting their investment to about 20 stocks. Table 6 presents the results of the relation between fund performance and diversification ratio, computed as described in Section 2.

The results show a positive relation between the funds' degree of diversification and overall performance. This result is found to be statistically significant both in the crosssectional analysis and the trading strategy. Moreover, I find similar but weaker results when the Small Cap and Sweden funds are examined separately.

Table 6 also presents a positive relation between the funds degree of diversification and tactical performance. This result is statistically significant for the trading strategy. A similar positive relation between tactical performance and the funds' degree of diversification is also revealed when Small Cap funds are examined separately. However, I do not find any relation between tactical performance and degree of diversification for Sweden funds. Finally, I find no relation between strategic performance (the replicating portfolio) and the degree of diversification.

\subsubsection{Other Investments}

In this section, I examine how investments outside the funds primary investment universe affect the performance of funds' in Sweden. Table 6 presents the result on the relation between the funds' 'other investments' and performance; the share of the portfolio that is invested outside the funds' primary investment universe is referred to as 'other investments' and mainly consists of non-listed firms, but also includes foreign stocks. 
A weak positive relation is found between the funds' overall performance and other investments. This result is partly caused by outliers and is not statistically significant when the trading strategy is employed. A similar result is obtained when Sweden funds are examined separately. The table also shows that no statistically significant results appear when tactical performance is examined.

The relation between fund performance and other investments is also interesting since substantial investments outside the funds' primary investment universe can raise a benchmark problem. For instance, Elton, Gruber, Das and Hlavka (1993) show that the high performance in Ippolito (1989) is due to a benchmark model that does not correspond to the evaluated funds' investment universe. Further, Elton, Gruber, Das and Hlavka (1993) show that the performance in Ippolito (1989) is lower when an appropriate model is used. Contrary to Elton, Gruber, Das and Hlavka (1993), the results in this evaluation of Sweden and Small Cap funds do not suggest that investment outside the funds primary investment universe affect the performance. Hence, the benchmark problem in Ippolito (1989) is not present here.

\subsubsection{Cash Holdings}

In this section, we examine the relation between the funds' cash holdings and performance. Mutual funds need to keep some cash holdings in order to handle net outflows. However, as we saw in Figure 1, the dispersion and magnitude of cash holdings cannot be motivated by flows. Other factors, such as a pessimistic fund manager, could affect the decision to hold cash. This is, of course, a risky decision since the manager will be punished if the raw returns are lower than the returns of the benchmark.

Table 6 shows that the cross-sectional analysis of overall performance to the funds' cash holdings suggests a positive relation. However, the statistical significance disappears when the trading strategy is employed. Further, I find no statistically significant results when the funds are examined separately based on investment objective. This suggests that the weak 
positive relation is due to the larger cash holdings and higher overall performance of Small Cap funds.

Table 6 also suggests that a weak positive relation exists between tactical performance and the funds cash holdings. That is, funds' that have large cash holdings at the beginning of the year make more successful tactical decisions. This result can once again be explained by the differences in the characteristics of Small Cap and Sweden funds, but it also proves to be statistically significant in the cross-sectional regressions for Sweden funds.

\subsection{Robustness Checks}

This section summarizes the robustness checks of the relation between performance and investment strategies that are based on the characteristics of the fund portfolio.

I start by examining whether the WLS estimates are robust, and specifically study how the regression results are affected by the inclusion or non-inclusion of outliers. For instance, I have reestimated the WLS regressions on every possible subsample of size $\mathrm{N}-2$ drawn from the entire sample of $\mathrm{N}$ observations. This gives $\mathrm{N}(\mathrm{N}-1) / 2$ different estimates, and I examine the distribution of these. Other approaches are estimations using the method of least absolute deviations (LAD) and the method of least trimmed squares (LTS), which put less weight on outliers. See, for instance, Rousseew and Leroy (1987) or Amemiya (1985) chapter 2 for further details on the estimators. This evaluation shows that outliers have a marginal effect on the significant WLS results. Further, in Table 1 we observed high correlations between some of the investment strategies; this could have an important effect on the results. I therefore examine the relation between alpha and investment strategy in a multiple setting. Two setups are considered: one multiple regression for asset pricing anomalies (e.g., market capitalization, three months' past return, and book-to-market ratio), and one for other characteristics of the portfolio (e.g., diversification ratio, other investments, and cash). These multiple regressions show that the 
significant results in the single regressions hold when the multiple regression is employed. Finally, these robustness checks provide support of the results in Section 4.

\section{Conclusions}

This paper has attempted to shed some light on how fund managers' investment strategies, which are characterized by observed portfolio holdings, affect the performance of Swedish mutual funds. The first part explored strategies that are related to the evidence on asset pricing anomalies, such as the momentum effect, the firm size effect, and book-tomarket effect. The study shows that a weak negative relation exists between performance and past stock returns in the portfolio. Further, there is some evidence that the highest performing Sweden funds invest to higher extent in smaller companies. This evidence can partly explain why we observe a negative fund-size effect in Dahlquist, Engström and Söderlind (2000). Moreover, investing in value stocks can help to improve overall performance.

The examination of the relation between the performance of the passive (strategic) portfolio and momentum, firm size, and valuation characteristics gives even weaker results compared with overall performance. This suggests that asset pricing anomalies related to momentum, firm size, and the valuation of stocks do not exist in Sweden.

The second part of the paper explores strategies that are related to the structure of the managed portfolio. One important investment strategy concerns the extent to which the portfolio manager should diversify. This paper shows that mutual funds with a more diversified portfolio perform somewhat better than funds with a less diversified portfolio. However, diversification can be achieved by extending the funds' investment universe and investing in non-listed stocks. Elton, Gruber, Das and Hlavka (1993) show that funds investing in these types of assets might achieve superior performance simply because these assets are not captured within the benchmark model. This paper, however, finds no evidence to indicate that investment outside the fund's primary investment universe will enhance 
performance. Moreover, the effects of cash holdings on performance are explored, and some weak evidence suggests that large cash holdings imply better tactical decisions.

\section{References}

Amemiya, Takeshi, 1985. Advanced Econometrics (Harvard University Press: Cambridge, Massachusetts).

Banz, Rolf W., 1981, The relationship between return and market value of common stocks, Journal of Financial Economics 9, 3-18.

Brennan, Michael J., Tarun Chordia, and Avanidhar Subrahmanyam, 1997, A re-examination of some popular security return anomalies, Working paper.

Conrad, Jennifer, and Grautham Kaul, 1998, An anatomy of trading strategies, Review of Financial Studies 11, 489-519.

Dahlquist, Magnus, Stefan Engström, and Paul Söderlind, 2000, Performance and characteristics of Swedish mutual funds, Journal of Financial and Quantitative Analysis 35, 409-423.

DeBondt, Werner F. M., and Richard H. Thaler, 1985, Does the stock market overreact, Journal of Finance 42, 427-465.

Elton, Edwin J., Martin J. Gruber, Sanjiv Das, and Matthew Hlavka, 1993, Efficiency with costly information: A reinterpretation of evidence from managed portfolios, Review of Financial Studies 6, 1-22.

Engström, Stefan, 2003, Costly information, diversification and international mutual fund performance, Pacific-Basin Finance Journal 11, 463-482.

Engström, Stefan, 2004, Does active portfolio management create value? An evaluation of fund managers' decisions, Working paper (Stockholm School of Economics).

Falkenstein, Eric G., 1996, Preferences for stock characteristics as revealed by mutual fund portfolio holdings, Journal of Finance 51, 111-135.

Fama, Eugene F., and Kenneth French, 1992, The cross-section of expected stock returns, Journal of Finance 47, 427-466.

Fama, Eugene F., and Kenneth French, 1996, Multifactor explanations of asset pricing anomalies, Journal of Finance 51, 55-84.

Fama, Eugene F., and Kenneth French, 1998, Value versus growth: The international evidence, Journal of Finance 53, 1975-1999.

Ferson, Wayne E., and Rudi Schadt, 1996, Measuring fund strategy and performance in changing economic conditions, Journal of Finance 51, 425-461. 
Grinblatt, Mark, Sheridan Titman, and Russ Wermers, 1995, Momentum strategies, portfolio performance, and herding: A study of mutual fund behavior, American Economic Review 85, 1088-1105.

Henriksson, Roy D., and Robert C. Merton, 1981, On market timing and investment performance II: statistical procedures for evaluating forecasting skills, Journal of Business 54, 513-534.

Heston, Steven L., K. Geert Rouwenhorst, and Roberto E. Wessels, 1995, The structure of international stock returns and integration in emerging markets, Journal of Empirical Finace 2, 173-197.

Ippolito, Richard A., 1989, Efficiency with costly information: A study of mutual fund performance, Quarterly Journal of Economics 104, 1-24.

Jegadeesh, Narasimhan, and Sheridan Titman, 1993, Returns to buying winners and selling losers: Implications for stock market efficiency, Journal of Finance 48, 65-91.

Jensen, Michael C., 1968, The performance of the mutual fund in the period 1954-1964, Journal of Finance 23, 384-416.

Lakonishok, Josef, Andrei Shleifer, and Robert Vishny, 1994, Contrarian investment, extrapolation and risk, Journal of Finance 49, 1541-1578.

Rousseew, Peter J., and Annick M. Leroy, 1987. Robust regression and outlier detection (John Wiley and Sons, New York).

Rouwenhorst, K. Geert, 1998, International momentum strategies, Journal of Finance 53, 267-284.

Treynor, Jack L., and Kay Mazuy, 1966, Can mutual funds outguess the market?, Harvard Business Review 44, 131-136. 
Table 1: Correlation of Investment Strategies

$\begin{array}{lllll}\text { Other } & \text { Div. } \\ \text { invest. } & \text { ratio }\end{array}$ Cash $\quad$ Ret. $3 \mathrm{M} \quad$ Mcap

\begin{tabular}{llllll} 
Diversification ratio & 0.27 & & & & \\
Cash & 0.05 & 0.25 & & & \\
Return 3 months & 0.17 & 0.14 & -0.06 & & \\
Market capitalization & 0.19 & -0.10 & -0.10 & 0.67 & \\
Book-to-market & 0.03 & -0.03 & -0.14 & -0.65 & -0.65 \\
\hline
\end{tabular}

This table shows the correlation of funds' investment strategies, which are based on annual characteristics of the fund portfolio. The investment strategies are other investments, cash, diversification ratio, return past 3 months, market capitalization, and book-to-market ratio. 
Table 2: Annual and Average Characteristics of Investment Strategies

\begin{tabular}{|c|c|c|c|c|c|c|}
\hline & 1996 & 1997 & 1998 & 1999 & 2000 & Average \\
\hline \multicolumn{7}{|c|}{ Panel A. All Funds } \\
\hline Other investments & 7.3 & 4.9 & 3.8 & 5.0 & 9.2 & 6.0 \\
\hline Diversification ratio & 27.8 & 30.7 & 31.3 & 31.5 & 32.4 & 30.7 \\
\hline Cash & 4.6 & 4.0 & 4.0 & 3.0 & 3.7 & 3.9 \\
\hline Return 3 months & -1.7 & 15.2 & -3.1 & 17.1 & 46.4 & 14.8 \\
\hline Market capitalization & 33 & 47 & 55 & 69 & 175 & 76 \\
\hline Book-to-market & 52 & 41 & 31 & 28 & 20 & 34 \\
\hline \multicolumn{7}{|c|}{ Panel B. Small Cap Funds } \\
\hline Other investments & 6.9 & 5.9 & 6.2 & 4.2 & 10.3 & 6.7 \\
\hline Diversification ratio & 31.2 & 39.6 & 35.9 & 40.6 & 42.1 & 37.9 \\
\hline Cash & 7.9 & 7.6 & 4.3 & 4.2 & 3.6 & 5.5 \\
\hline Return 3 months & -1.0 & 22.9 & 0.4 & 12.1 & 54.0 & 17.7 \\
\hline Market capitalization & 7.5 & 6.6 & 6.3 & 6.9 & 3.7 & 6.2 \\
\hline Book-to-market & 54 & 42 & 33 & 33 & 23 & 37 \\
\hline \multicolumn{7}{|c|}{ Panel C. Sweden Funds } \\
\hline Other investments & 7.4 & 4.7 & 3.4 & 5.1 & 9.1 & 5.9 \\
\hline Diversification ratio & 27.3 & 29.5 & 30.5 & 29.8 & 30.9 & 29.6 \\
\hline Cash & 4.2 & 3.5 & 3.9 & 2.8 & 3.7 & 3.6 \\
\hline Return 3 months & -1.8 & 14.1 & -3.8 & 18.1 & 45.2 & 14.4 \\
\hline Market capitalization & 36 & 52 & 63 & 80 & 202 & 87 \\
\hline Book-to-market & 52 & 41 & 31 & 28 & 19 & 34 \\
\hline
\end{tabular}

This table shows annual and average characteristics of the funds' investment strategies. The investment strategies are based on other investments, cash, diversification ratio, return past 3 months, market capitalization, and book-to-market ratio. All the characteristics are expressed in percentage except market capitalization, which is in SEK billion. 


\section{Overall \\ Performance \\ Strategic Performance Tactical Performance}

Ret. 1

Y

Ret. 3 M

Ret. 1 Y

Ret. 3 M

Ret. 1 Y

Ret. 3 M

$\underline{\text { Single Panel Regressionst }}$

Coefficient $\quad-14.38$

Standard error

(2.75)

$-20.02$

$-4.15$

$-6.88$

$-5.38$

$-6.11$

(6.96)

(2.67)

$(6.53)$

(2.11)

Performance of Trading Strategies:

Alpha $\quad-1.41 \quad 0.64$

Standard error

(2.01)

(2.73)

$-0.62$

0.98

$-0.99$

$-0.25$

(2.08)

(2.76)

(1.24)

This table relates estimated annual overall alphas, strategic alphas, and tactical alphas to annual investment strategy of the fund, which is based on past stock returns.

$\dagger$ The single panel regression is a regression of the alpha on a constant and each attribute individually allowing for fixed year effects. The equation (2) is estimated with weighted least squares, where each observation is weighted by the inverse of the standard deviation of the estimated alpha. The slope coefficient is reported and the corresponding heteroskedasticity-consistent standard error is shown in parentheses below the coefficient. The number of observations in the regressions is 451 .

\$ The trading strategy is to buy (with equal weights) funds above the 75 th percentile of the attribute, and sell (with equal weights) funds below the 25 th percentile. The performance of the trading strategy is estimated in the same way as the performance of the funds, and the conditional alpha is reported. The corresponding heteroskedasticity-consistent standard error is shown in parentheses below the alpha. 


\begin{tabular}{cccccc}
\multicolumn{2}{c}{ Overall } & \multicolumn{2}{c}{ Strategic Performance } & \multicolumn{2}{c}{ Tactical Performance } \\
Performance & \multicolumn{2}{c}{ Mtran vol } \\
Mcap & $\begin{array}{c}\text { Mean } \\
\text { vol }\end{array}$ & Mcap & Mean vol & Mcap & Mean vol
\end{tabular}

$\underline{\text { Single Panel Regressionst }}$

\begin{tabular}{lllcccc}
\hline Coefficient & -0.58 & -0.51 & 0.09 & 0.15 & -0.66 & -0.61 \\
Standard error & $(0.33)$ & $(0.33)$ & $(0.39)$ & $(0.35)$ & $(0.22)$ & $(0.20)$
\end{tabular}

Performance of Trading Strategies:

\begin{tabular}{llllccc}
\hline Alpha & -1.50 & -1.42 & 1.93 & 2.10 & -3.36 & -3.44 \\
Standard error & $(2.01)$ & $(1.97)$ & $(2.39)$ & $(2.37)$ & $(1.50)$ & $(1.43)$
\end{tabular}

This table relates estimated annual overall alphas, strategic alphas, and tactical alphas to the annual investment strategy of the fund, which is based on firm size. For details, see Table 3.

Table 5: Performance and Valuation of Firms

\begin{tabular}{cccrcr}
\multicolumn{2}{c}{ Overall } & \multicolumn{2}{c}{ Strategic Performance } & \multicolumn{2}{c}{ Tactical Performance } \\
Performance & & & & \\
B t M & Div & B t M & Div Yield & B t M & Div Yield
\end{tabular}

$\underline{\text { Single Panel Regressionst }}$

$\begin{array}{lcccccc}\text { Coefficient } & 18.19 & 3.81 & 7.54 & 2.13 & 1.49 & 0.96 \\ \text { Standard error } & (3.51) & (0.82) & (4.33) & (1.03) & (3.39) & (0.79)\end{array}$

Performance of Trading Strategiest

$\begin{array}{lcccccc}\text { Alpha } & 1.38 & 0.45 & -0.62 & 1.08 & 2.01 & -0.62 \\ \text { Standard error } & (1.61) & (2.01) & (1.62) & (2.11) & (1.12) & (1.36)\end{array}$

This table relates estimated annual overall alphas, strategic alphas, and tactical alphas to the annual investment strategy of the fund, which is based on the valuation of stocks. For further details, see Table 3. 
Table 6: Performance and other Investment Strategies

\section{Overall Performance

\begin{tabular}{|c|c|c|c|}
\hline Cash & $\begin{array}{l}\text { Other } \\
\text { invest }\end{array}$ & Div ratio & Cash \\
\hline
\end{tabular}

$\underline{\text { Single Panel Regressionst }}$

$\begin{array}{lcccccc}\text { Coefficient } & 10.33 & 5.88 & 7.83 & 16.55 & -1.32 & 2.16 \\ \text { Standard error } & (5.82) & (2.96) & (2.85) & (5.68) & (2.76) & (2.62)\end{array}$

Performance of Trading Strategiest:

\begin{tabular}{lcccccc}
\hline Alpha & 1.41 & -0.23 & 2.67 & 1.01 & -0.12 & 2.60 \\
Standard error & $(1.40)$ & $(1.38)$ & $(1.18)$ & $(0.89)$ & $(1.21)$ & $(1.13)$
\end{tabular}

This table relates estimated annual overall alphas and tactical alphas to the annual investment strategy of the fund (diversification ratio, other investments, and cash holdings). For further details, see Table 3.

Figure 1: Distribution of the Funds' Liquidity

The figure shows the distribution of 459 annual observations of liquidity or cash holdings in the fund portfolios. 17 portfolios have cash holdings above $12 \%$ of total assets.

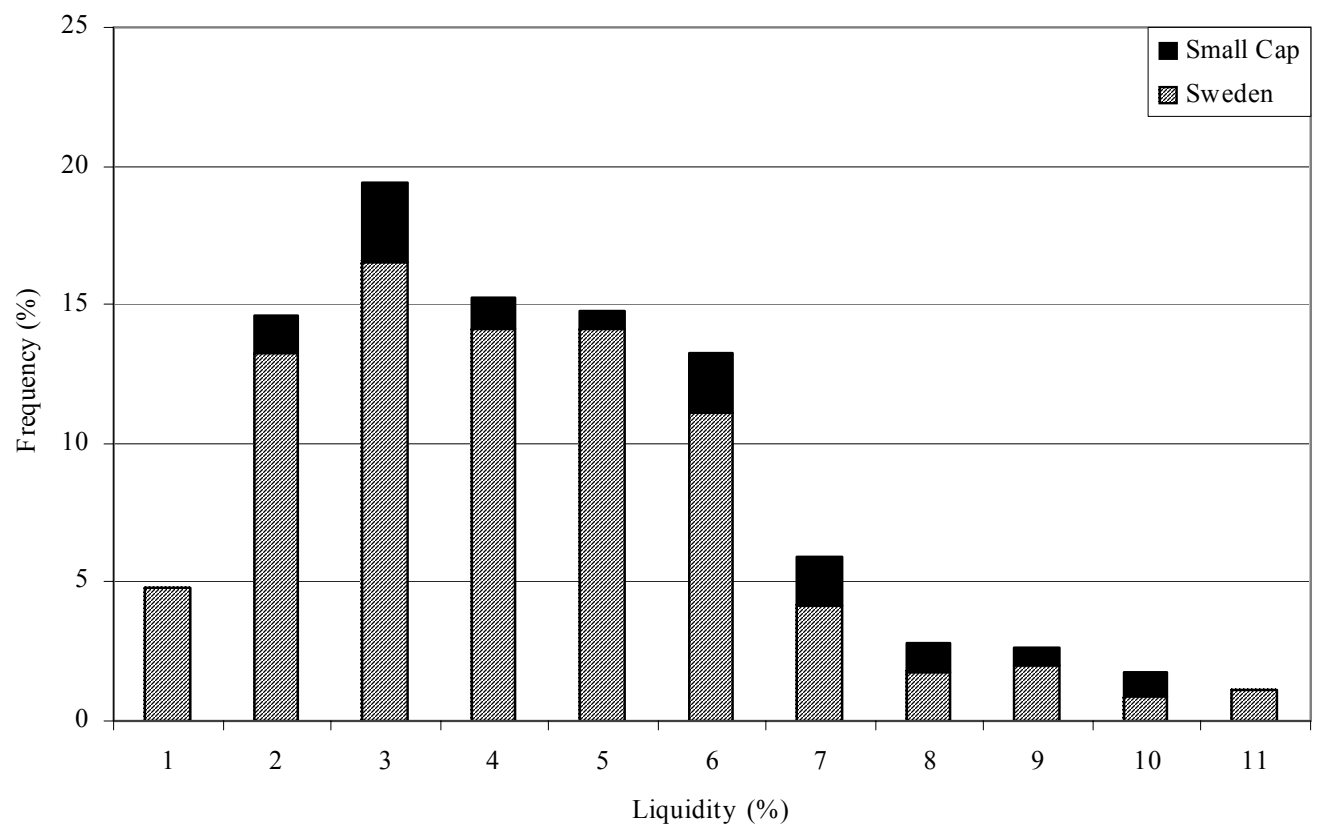


Figure 2: Distribution of the Funds' Diversification Ratio

The figure shows the distribution of the diversification ratio; 398 annual observations refer to Sweden funds and 62 refer to Small Cap funds.

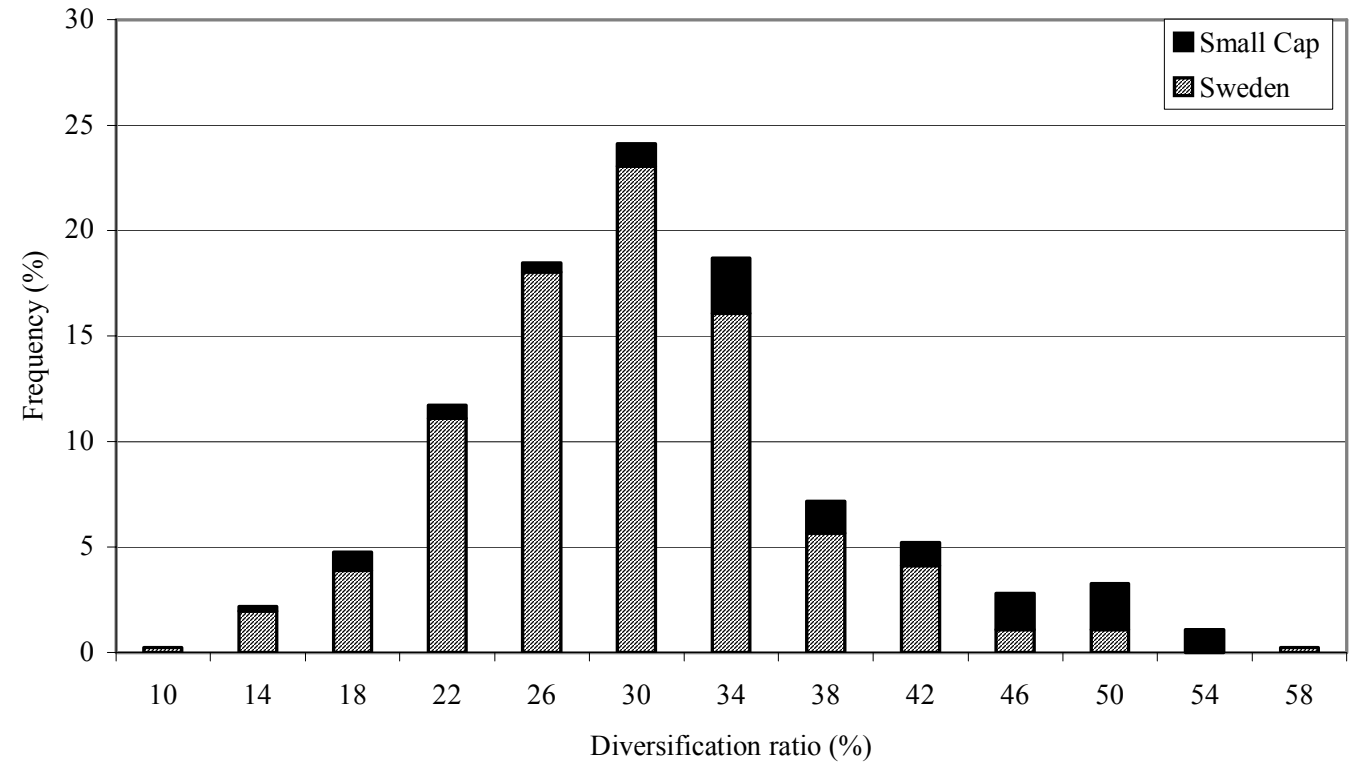

Figure 3: Distribution of the Funds' Other Investments

The figure shows the distribution of 460 annual observations of portfolio holdings of other investments. Thirty portfolios have more than $20 \%$ of the portfolio invested in other investments.

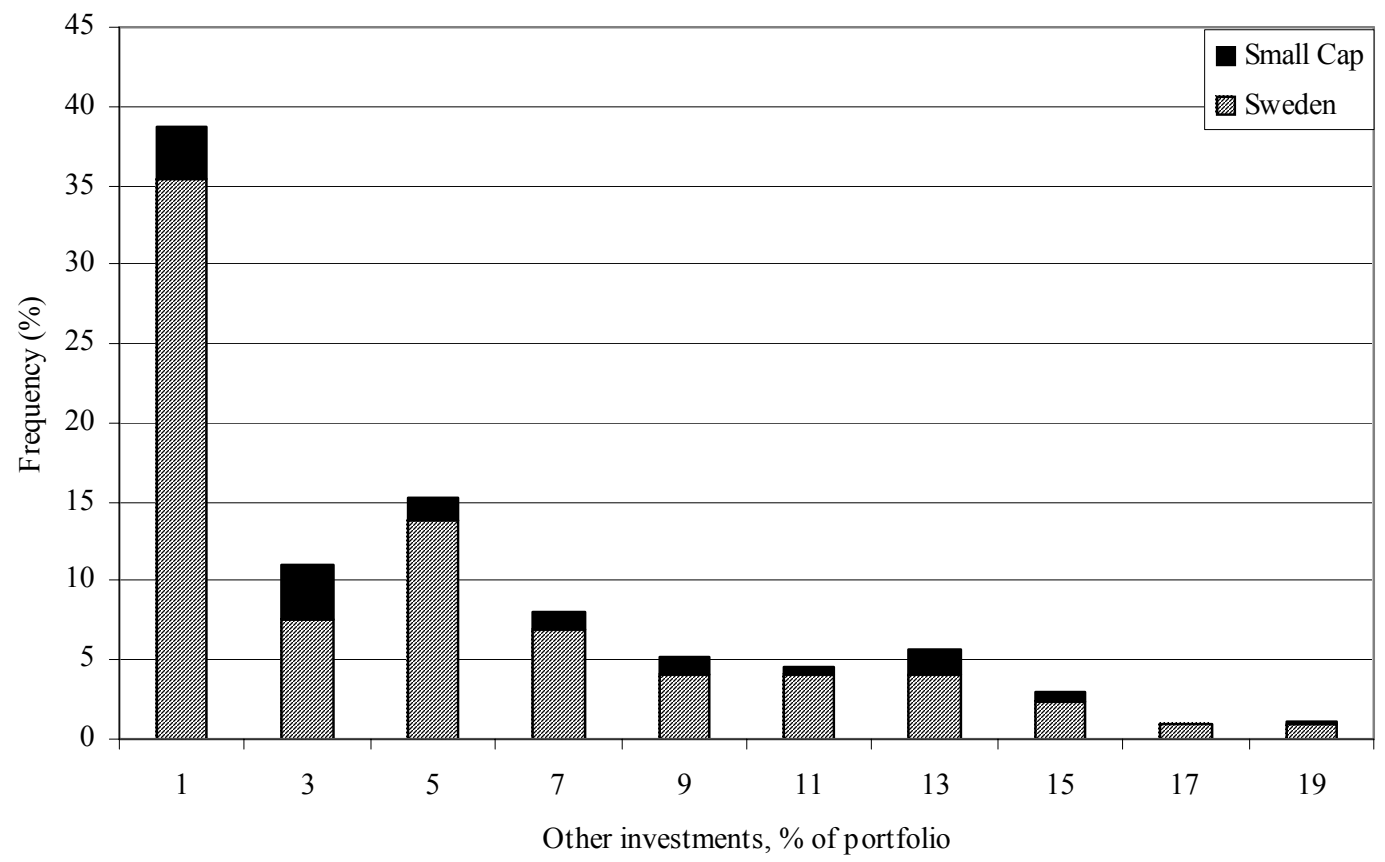


Figure 4: Distribution of Overall Performance

The figure shows 112 estimated conditional alphas for the sample of funds from 1996 to 2000 . The alphas are separated based on the investment objectives, Small Cap and Sweden. One alpha is higher than $16 \%$.

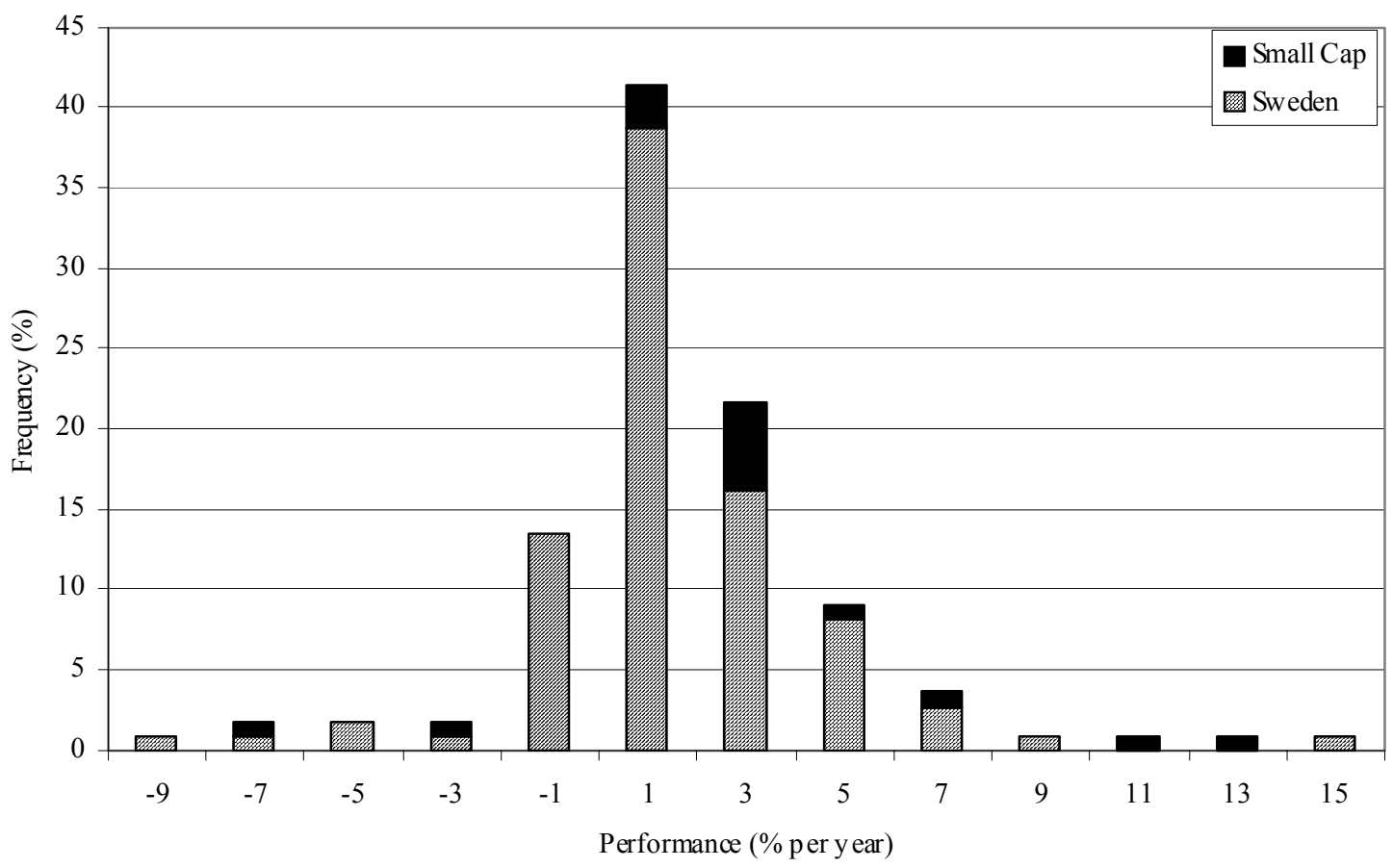

